\title{
POLÍTICA E ECONOMIA NA AÇÃO COLETIVA: UMA CRÍTICA ETNOGRÁFICA ÀS PREMISSAS DICOTÔMICAS
}

Julieta Quirós

As transformações no mundo do trabalho e a irrupção do desemprego estrutural na Argentina (cf. Beccaria \& López 1996) foram acompanhadas por deslocamentos no eixo do conflito social: na última década, emergiram e proliferaram organizações de desempregados, organizações que fizeram do trabalho sua demanda distintiva em face do Estado e do piquete de rutabloqueio e ocupação de estradas - seu principal método de protesto. Desde seus princípios - em 1996, quando os bloqueios de estradas concentravamse em pontos específicos do interior do país - os chamados piqueteros ${ }^{+}$ foram objeto de debate público. Primeiro, a discussão girava em torno da legitimidade ou não de uma ação de protesto que pode ser enquadrada em figuras penais como sedição e "intimidação pública" (Manzano 2007:267). Depois, quando as organizações de desempregados consolidaram-se nos subúrbios das grandes cidades do país e quando, desde o ano 2000, o piquete generalizou-se como ação de protesto, passou-se a perguntar com mais ênfase quem são esses piqueteros e por que bloqueiam estradas - questões estas que deram origem a um acalorado debate midiático e político. ${ }^{1} \mathrm{O}$ interesse pelo fenômeno alcançou também o campo das ciências sociais, gerando uma explosão bibliográfica sobre o que se denominou "novas formas de protesto social" e "novos movimentos sociais". ${ }^{2}$

+[N. T.] Escolheu-se, na maior parte do tempo, manter na tradução o termo piquete, bem como piquetero, por não se haver encontrado vocábulo cotidiano que se refira, no Brasil, ao bloqueio de estradas, avenidas ou ruas. Para salientar a utilização de palavra estrangeira, os termos virão em itálico. Cabe ressaltar que, na Argentina de hoje, o piquete tem significado distinto de seu habitual sentido no Brasil, onde é frequentemente empregado em referência à ação de pessoas que, em greve, procuram impedir a entrada de outros trabalhadores no local de trabalho. Esta última acepção, contudo, também é admitida na língua espanhola, na qual este artigo foi originalmente escrito. 
Quando, em princípios de 2005, iniciei minha pesquisa sobre o tema, e especificamente meu trabalho de campo em Florencio Varela, ${ }^{3}$ município ao sul da Grande Buenos Aires, percebi que os chamados piqueteros estavam acostumados a receber visitas de espécies como o antropólogo. Na primeira vez em que me apresentei numa sede local de um dos movimentos piqueteros do distrito, uma de minhas interlocutoras comentou que poucas semanas antes haviam estado ali "uns franceses", que tinham se hospedado no lugar e que durante algum tempo acompanharam as atividades da organização: Tiraram fotos nossas e tudo - acrescentou a mulher - você quer fazer algo assim, não ${ }^{4}$

Este tipo de comentário, como os que me associavam aos "jornalistas" e aos "sociólogos", seria uma constante ao longo do trabalho de campo que então começava. Minha identificação com os estrangeiros indicava, ademais, que o interesse pelos piqueteros transcendia as fronteiras nacionais. "Os franceses" - às vezes "os alemães", "os dinamarqueses" - eram um dos muitos grupos de intelectuais, ativistas antiglobalização e militantes de novas esquerdas que dia a dia chegam para compartilhar experiências com aquilo que pode ser a multidão, a potência ou uma nova forma de resistência ao capitalismo global. Talvez o mais significativo na recorrente associação a esses visitantes fosse o que se denotava a respeito das expectativas que os piqueteros tinham de mim. Em poucos dias, meus interlocutores perceberiam que minhas caminhadas pelos bairros de Florencio Varela incluíam encontros com outros movimentos de desempregados, outras organizações de bairro e com militantes e cabos eleitorais locais do Partido Justicialista (PJ). ${ }^{5}$ Esse procedimento pareceria estranho para muitos companheiros: Por que não visita outros locais do movimento? - perguntavam alguns. Os alemães vão a todas as reuniões e assembleias - advertiam-me outros. Você não pensou em entrevistar Martino? - perguntou-me uma mulher, referindo-se ao dirigente do movimento. Ele pode te dar uma visão geral de como nos organizamos.

Meu procedimento parecia estranho, entre outras coisas, porque meus interlocutores estavam habituados ao modo como os pesquisadores costumam abordá-los: refiro-me ao recorte que toma como unidade de análise o movimento, procurando dar conta de sua dinâmica cotidiana, de suas performances de protesto, de suas definições políticas. Mesmo que os estudos acadêmicos sobre piqueteros constituam um campo heterogêneo e partam de preocupações distintas ${ }^{6}{ }$ entendo que um elemento comum reside na natureza do objeto que recortam: um "ator coletivo" - o movimento ou os movimentos. Com base na análise de um conjunto de ideias e práticas que se enquadram "no(s) movimento(s)" — bloqueio de estradas, assembleias, 
atividades produtivas, documentos oficiais das organizações, entrevistas com militantes e dirigentes — os "piqueteros" são estudados como "piqueteros", uma "nova identidade social", definida pelo que se presume que essas pessoas fazem: "piquetes". ${ }^{7}$

Assim, a preocupação em definir e classificar a diversidade de organizações piqueteras atravessa boa parte dessa bibliografia — tarefa classificatória que tende a reproduzir os termos das disputas entre os próprios dirigentes e acaba transformando os movimentos em sujeitos que pensam, concebem, dizem, reivindicam, aceitam, rechaçam e julgam. Como resultado, e com raras exceções (veja-se, por exemplo, Auyero 2002b, 2004; Manzano 2007), as organizações são isoladas do universo social concreto de que fazem parte e, sobretudo, da vida daqueles que as constituem. ${ }^{8}$

Se a sociologia do fenômeno piquetero tem sido predominantemente uma sociologia dos movimentos, este texto inscreve-se num ponto de vista alternativo, que busca restituir, através de uma perspectiva etnográfica, a dimensão vivida da ação coletiva, explorando uma série de experiências cotidianas entre aqueles que se engajam em organizações de desempregados. A proposta não significa desagregar e substituir o sujeito "movimento" pelo sujeito "piqueteros", mas partir do pressuposto relacional de que não podemos compreender como as pessoas vivem seu engajamento numa organização piquetera ou como se dispõem a participar dessas grandes ações de protesto, se não nos voltarmos também para o que acontece além dos limites da organização e fora do piquete, ou seja, se não inscrevermos essa experiência num conjunto mais amplo de relações sociais e possibilidades de vida (cf. Quirós 2006).

Em meu campo etnográfico, descentrar o olhar dos movimentos implicou, entre outras coisas, considerar que o universo social no qual desenvolvia meu trabalho era marcado não só pela situação de desemprego estrutural, subemprego e trabalho precário, mas também por uma onipresença estatal específica: a generalidade dos planos de emprego ou dos planos sociais para desempregados. ${ }^{9}$ Em Florencio Varela, o plano revelava-se um meio de vida generalizado e também uma linguagem coletiva: inscrever-se no plano, esperá-lo, recebê-lo, cobrar, dar baixa, perdê-lo eram signos dessa linguagem, como também as fotocópias dos documentos de identidade a serem apresentadas ao governo, ou as planilhas e os comprovantes de presença às tarefas de contraprestação estabelecidas para cada beneficiário. As organizações piqueteras eram parte constitutiva desse mundo, pois eram um dos atores que permitiam às pessoas aceder aos planos; em Florencio Varela, podia se obter um plano por meio de um político, ou inscrevendo-se nos registros da prefeitura, ou também inscrevendo-se em algum movimento piquetero. ${ }^{10}$ 
Em breve, perceberia que o plano era um dos recursos mediante os quais se enredavam (e desenredavam) múltiplas relações de interdependência: entre vizinhos, parentes, agentes estatais, organismos municipais, cabos eleitorais, políticos e organizações piqueteras. Veria também que, por meio dessas relações, meus interlocutores circulavam por distintos espaços, transcendendo fronteiras organizacionais e desafiando classificações sociológicas. Enquanto a literatura se ocupava em demarcar diferenças entre as diversas organizações piqueteras, Florencio Varela mostrava-me que as pessoas podem circular entre elas e que não necessariamente estão segmentadas conforme seu pertencimento a um movimento. Enquanto a literatura distanciava - e opunha — os piqueteros (participantes dos movimentos sociais) dos punteros (do Partido Justicialista), ${ }^{11}$ meus interlocutores no campo por vezes se apresentavam em situações e relações nas quais estes rótulos podiam ser postos entre parênteses.

Em certo momento, supus que meu recorte empírico e analítico era territorial - o bairro - em vez de corporativo — os movimentos. Contudo, o circuito que meu trabalho de campo seguiu não respeitou fronteiras territoriais, mas configurou-se por intermédio dessas relações de parentesco, vizinhança e interconhecimento que permitiam a meus interlocutores - e a mim - transitar por espaços diferenciados, embora nem sempre ou necessariamente excludentes. A unidade que de fato recortei não era substantiva (o movimento, o bairro, as pessoas), mas relacional, e pode ser concebida, seguindo Elias (1991), como uma figuração, uma trama de dependências recíprocas que conecta as pessoas em múltiplas direções.

Este artigo trata de fragmentos dessa figuração em ação e, por meio deles, discute alguns hábitos epistemológicos que permeiam os estudos sobre piqueteros, em particular, e sobre ação coletiva e movimentos de protesto, em geral. Explorando uma série de relações que se atualizam em objetos como $o$ plano, questiono primeiro a cisão entre "economia" e "política", com base na qual a academia vem formulando suas perguntas e suas respostas ao fenômeno piquetero. Em seguida, desconfio da oposição rígida entre o Estado e os movimentos, mostrando o poder criador - e não somente cooptador — das políticas e dos programas estatais; neste sentido, exponho algumas limitações da conceitualização dos movimentos como "mediadores" ou "intermediários" entre o Estado e a população. Finalmente, expresso a necessidade de sociologizar, além da "política" e da "economia", outras dimensões da ação coletiva, e proponho, como primeiro passo, a incorporação do prazer de fazer como elemento-chave na gênese e na dinâmica do engajamento político.

Mais que novas respostas a velhas questões, pretendo com esta discussão apontar novas perguntas com as quais os fenômenos que enquadramos 
no campo da "ação coletiva" e dos "movimentos sociais" podem ser examinados. Meu argumento desenvolve-se, a seguir, com base em situações etnográficas concretas. Parece-me importante advertir o leitor sobre essa articulação intrínseca entre as reflexões conceituais e a trama etnográfica que apresento, já que as ideias que vou defendendo não se separam do "caso": é mediante a vida de alguns de meus principais interlocutores no campo o casal Aguirre e seus sete filhos ${ }^{12-}$ e de uma série de experiências com eles compartilhadas que exponho meus argumentos.

\section{Estar com os piqueteros: armadilhas de um consenso dicotômico}

Numa de minhas primeiras visitas a Varela, tive a oportunidade de acompanhar a ocupação de um lugar abandonado, organizada pelo Movimento Teresa Rodríguez (MTR, de agora em diante), uma das organizações piqueteras mais importantes do distrito. Um dia antes, numa reunião da qual participaram vizinhos pertencentes ou não ao movimento, Claudia, dirigente do MTR, anunciou a iniciativa de realizar a ocupação: o objetivo, informou, era o de transformar o lugar em centro cultural onde funcionassem oficinas para os possíveis beneficiários — jovens de 12 a 25 anos — com uma bolsa de 75 pesos mensais que, conforme disse, seria outorgada pelo

governo nacional. Com um centro cultural em funcionamento - foi afirmado na reunião - as bolsas sairiam mais rapidamente. No primeiro dia da ocupação, conheci Matilde Aguirre, que lá se encontrava desde o início da manhã com três de seus sete filhos. Durante esse período, havia limpado o local e preparado o almoço para os companheiros. Talvez por essa atuação intensa, mais tarde me surpreenderia ao saber que Matilde não estava no movimento: Quem está com os piqueteros é meu pai - disse-me Vero, de 15 anos, a filha mais velha do casal. E acrescentou: Como ele está agora fazendo uns bicos com o carrinho de mão, minha mãe vem e ajuda, mas ela tem um plano da UGL.

"UGL" seria uma das siglas que mais ouviria durante minhas visitas a Varela. Um funcionário do município explicou-me que as UGLs (Unidades de Gestão Local) fazem parte do programa de Gestão Participativa e "são como pequenas sedes da prefeitura que, distribuídas em cada bairro, procuram melhorar a comunicação entre a comunidade e o prefeito". Enquanto isso, nos bairros, as pessoas costumavam definir as UGLs em outros termos: São os planos que o governo dá - explicou-me Vero Aguirre certa vez. As pessoas recebem esses planos, mas sem fazer nada, enquanto os piqueteros recebem pelas passeatas. ${ }^{13}$ Outros muitos responderiam que as UGLs eram "os planos 
da prefeitura", resposta que continha uma associação entre as UGLs e os planos vinculada ao fato de que a grande expansão dessas entidades locais se deu a partir de 2002, quando os municípios, por disposição do governo nacional, foram o primeiro canal distributivo do recém-criado Plan Jefas y Jefes de Hogar Desocupados (Plano Homens e Mulheres Chefes de Família Desempregados). Este plano de emprego, sob a declaração de "Emergência Ocupacional Nacional", chegou a contar com 2 milhões de beneficiários em todo o país. Em Florencio Varela, as UGLs foram os organismos encarregados de executar o programa, cadastrando os beneficiários e determinando as contraprestações em forma de tarefas para o bairro e a comunidade.

Originalmente não era Matilde Aguirre, mas Juan, seu marido, quem tinha o plano da UGL. Quando Juan ficou doente, Matilde começou a substituí-lo na contraprestação, para assegurar a continuidade dos pagamentos. Tempos depois, a UGL regularizou a sua situação e fez dela a beneficiária do plano: E, como a UGL não estava mais dando planos - disse-me Juan certa vez - fui me inscrever nos piqueteros. Como todo aspirante a um plano por meio de um movimento, ao inscrever-se nos piqueteros, Juan começou a participar das passeatas e dos bloqueios de estradas. Matilde me contou que, quando Juan "entrou para os piqueteros, vivia noite e dia no movimento, ia aos acampamentos, aos bloqueios, às vezes ficava três ou quatro dias sem aparecer. O que você tanto faz nesse movimento? Por que tem que ir lá, fazer arruaça com esses piqueteros?" — repreendia-o Matilde. O marido respondia que "assim iam dar o plano".

Juan havia entrado na lógica do movimento, segundo a qual a quantidade de mobilizações de que se participa é diretamente proporcional à possibilidade de obter o esperado benefício. Inscrever-se nos piqueteros é ingressar num sistema de relações e obrigações recíprocas, e participar das passeatas é, em tese, a condição para ter, num futuro mais ou menos incerto, direito a um plano. A desconfiança inicial de Matilde Aguirre em relação aos piqueteros revela esse tanto de crença e dúvida, certeza e incerteza, que caracteriza a entrada em um movimento. Incerteza em função da qual alguns desistem depois de estar participando das passeatas por algum tempo (Os piqueteros me enganaram, me prometeram um plano que nunca saiu ouvi em certa ocasião em Varela), enquanto outros permanecem e outros ainda, depois de terem desistido, voltam para o movimento ao saberem que, finalmente, o plano chegou.

A forma como Juan Aguirre - tal qual Matilde - narrava sua aproximação com um movimento não era novidade para mim; surpreendia-me precisamente a recorrência dessa fórmula. Em primeiro lugar, inscrever-se nos piqueteros e estar com os piqueteros era o modo como os Aguirre e muitos 
outros classificavam sua relação e o desempenho de atividades dentro de um movimento. Se nos primeiros dias de meu trabalho de campo cometia o equívoco de perguntar a meus interlocutores se eles "eram do movimento", com o tempo percebi que aquilo que eu chamava de movimento podia ser um outro - os piqueteros - e que as pessoas, em vez de ser de, referiamse ao que faziam como estar com. Os prismas identitários - que dominam a literatura sobre os piqueteros — não só pareciam empobrecer a realidade oscilante que eu estudava, mas também constituíam, em relação a meus interlocutores, o que Florence Weber (1991:183) designaria como uma "violência interpretativa". É neste sentido que me interessa recuperar a expressão nativa estar com os piqueteros: as próprias pessoas me indicavam que, mais do que uma identidade ou uma trajetória, ela constitui uma multiplicidade de relações e identificações, sempre parciais.

Em segundo lugar, a maneira como Juan Aguirre narra sua aproximação com os piqueteros - "a UGL não estava mais dando planos" — advertiu-me sobre a importância de refletir acerca de sua participação no movimento como uma possibilidade que ganha sentido na relação com outras. À medida que transcorria meu trabalho, ficava claro que o plano era o que havia incorporado o estar com os piqueteros ao "horizonte dos possíveis"14 de muitos de meus interlocutores: E aí uma vizinha me disse que os piqueteros estavam dando planos, então vim e me inscrevi — diziam-me alguns. O plano dos piqueteros saiu para minha irmã, então vim também e me inscrevi — diziam-me outros. Minha cunhada me disse que viesse e me inscrevesse nos piqueteros, mas não gosto dessa história de manifestação.

Desde o início, a importância que o plano tinha na forma como as pessoas narravam a sua aproximação e também o seu distanciamento em relação aos movimentos foi analiticamente problemática para mim — provavelmente porque eu não estava alheia a um debate sociológico e político que, quase invariavelmente, tende a dissolver a questão em premissas normativas. No contexto de uma disputa para definir quem são esses piqueteros e por que participam dos piquetes, a literatura acadêmica procura tomar posição diante do que Thompson (1998:150) chamaria de "visão espasmódica" da ação popular: visão que reduz a mobilização coletiva a uma reação mecânica à necessidade, e as práticas dos setores populares a motivações meramente instrumentais. Quanto ao debate público e político sobre os piqueteros, assinalei que esta visão pretende explicar e invalidar os protestos, apelando para uma "razão material" (Quirós 2006:28-ss): vai-se à manifestação por um plano, por cestas de mercadorias ou, inclusive, por 20 pesos. Os dirigentes das organizações e a literatura acadêmica opõem a esta razão material uma razão "ideológica" ou "política" — as manifestações são motivadas pela busca por 
um trabalho genuíno, uma mudança social, uma nova institucionalidade e diferenciando a (mera) luta reivindicativa (por recursos de subsistência) da (verdadeira) luta política (por uma nova ordem social).

Mesmo quando alguns autores (cf. Masseti 2004; Svampa \& Pereyra 2004; Grimson et alii 2003) apontam para a heterogeneidade das bases dos movimentos piqueteros e para a diversidade de sentidos que seus protagonistas podem atribuir aos protestos, raramente se procura compreender com cuidado os motivos do engajamento dessas pessoas. Em geral, tende-se a fundi-los - e nesse sentido a ocultá-los - tanto nas palavras de ordem e nas bandeiras políticas proclamadas pelos movimentos (mudança social, por exemplo), quanto nos resultados de contestação que podem vir a ter as manifestações de protesto - como contra o sistema neoliberal. Quando a dimensão "subjetiva" da ação coletiva é eventualmente contemplada, geralmente é considerada em termos "simbólicos" e/ou "morais", fazendo-se menção, por exemplo, aos efeitos de afirmação identitária e de dignificação gerados pelo pertencimento a um movimento. A ordem moral também se incorpora à análise, já não tanto como efeito, mas como motivação, pelas perspectivas biográficas preocupadas em restituir o ponto de vista das pessoas que participam das ações de protesto (veja-se Auyero 2002b, 2004). "Visibilidade social", "reconhecimento", "dignidade" são aqui algumas das razões propostas como explicação alternativa não só à visão materialista (e espasmódica), mas também à visão politicista (e racionalizante) do engajamento.

Entendo que a cisão entre "razão material" e o que poderíamos chamar de "razão político-moral" forjou pouco a pouco, explícita ou implicitamente, a matriz classificatória e normativa com base na qual a academia examinou os objetivos do "ator coletivo" e as motivações dos "atores individuais". Esquema dicotômico que, como indica Manzano (2007:301), faz parte das premissas fundadoras do campo dos novos movimentos sociais e "atua, ainda, como geradora de perguntas e interpretações sobre os processos políticos protagonizados pelos 'setores populares'". Interessa-me sublinhar que tanto os partidários da razão material quanto os da razão político-moral compartilham uma série de consensos implícitos. Em primeiro lugar, ambas as posições hierarquizam as motivações e/ou os objetivos em jogo, e pressupõem, por exemplo, que a luta por um plano de 150 pesos ou por uma cesta de mercadorias é menos "política", menos "coletiva" (e menos "sociológica") que a luta por trabalho genuíno ou por mudança social.

Em segundo lugar, as duas posições refletem uma divisão prescritiva entre o que entendem por economia (universo que consideram ligado à subsistência e ao interesse) e por política (domínio que presumem ligado 
à vocação e à ação desinteressada), enquanto os partidários da razão material reprovam a "mistura" de ambas as ordens mediante a denúncia - a centralidade dos planos de emprego nos protestos piqueteros sendo sinal de uma política mercantilizada ou clientelista - e os defensores da razão político-moral a censuram mediante o tabu — os planos constituindo um aspecto subsidiário, uma demanda (meramente) reivindicatória por trás da qual repousam as demandas autênticas (e mais elevadas). Finalmente, estas posições partilham da premissa normativa de que o vínculo político não deveria estar marcado pela troca - ideal curioso, se levarmos em conta que teorias fundacionais da sociologia e da antropologia localizam na troca (de bens tangíveis e intangíveis) a gênese e a manutenção do laço social (cf. Mauss 2003; Lévi-Strauss 1967; Malinowski 1935).

O consenso dicotômico em torno do qual gravitam as perguntas e as respostas dos estudos sobre piqueteros, em particular, e sobre ação coletiva e movimentos de protesto social, em geral, poderia ser apresentado nos seguintes termos:

\begin{tabular}{|l|l|}
\hline Política & Economia \\
\hline Razão ideológica e/ou razão moral & Razão material \\
\hline Compromisso & Necessidade \\
\hline Altruísmo & Interesse \\
\hline Coletivo ou social & Individual \\
\hline Voluntário & Obrigatório \\
\hline Autonomia — Transformação & Heteronomia — Reprodução \\
\hline
\end{tabular}

Em relação especificamente à literatura argentina, arrisco dizer que a inclinação em direção à primeira coluna do quadro tem dupla ancoragem: uma, propriamente política, fundada na convicção de que esse é o caminho para legitimar as organizações e advogar por elas a partir do campo acadêmico; outra, teórica, em meu entender, fundada numa dupla vertente. Por um lado, a influência dos enfoques europeus que, distanciando-se da abordagem racionalizante das teorias norte-americanas (como as teorias da mobilização de recursos e das oportunidades políticas de Charles Tilly e Sidney Tarrow), propuseram incorporar "fatores culturais" ao estudo da ação coletiva - dimensões expressivas e cognitivas, como identidade e reconhecimento (cf. Melucci 1994, 1995). Como assinalam alguns autores 
(Polleta \& Jasper 2001:284; Brubaker \& Cooper 2000:6), a "identidade" operou, contrapondo-se ao "interesse" como modo de conceituar formas não-instrumentais e não-materiais do agir político. Por outro lado, a inclinação em direção à razão político-moral da literatura parte, diria, de certa leitura da "economia moral" de Thompson, leitura segundo a qual toda economia tem uma dimensão moral — no sentido de portar valores — que o sociólogo deveria desvelar. ${ }^{15}$

A discussão política com o reducionismo material, a centralidade das dimensões culturais e expressivas da ação coletiva e a obrigação de contemplar o que se convencionou chamar de moralidade da economia abonou o pressuposto tácito de que pode ser sociológica e politicamente perigoso outorgar um lugar significativo, no estudo da ação coletiva, à ordem material - tanto no que se refere às necessidades de subsistência dos "atores individuais", quanto às lutas reivindicativas do "ator coletivo". Em minha primeira aproximação com a questão piquetera (Quirós 2006), deparei-me com esse pressuposto e assinalei a importância de não desmerecer o lugar ocupado por recursos de subsistência como o plano, atendendo, em primeiro lugar, ao princípio etnográfico de considerar a forma como as pessoas vivem e dão sentido às suas práticas. Conforme este princípio, negar a centralidade do plano seria incorrer, uma vez mais, numa violência interpretativa.

Em segundo lugar, atendendo a uma postura política, subestimar o lugar do plano seria negar as condições sociais e econômicas concretas com as quais meus interlocutores - com inefável esforço e criatividade — lidam diariamente. Sobre este fundamento, argumentei que era estéril explicar o procedimento das pessoas com base em "razões" unívocas e procurei demonstrar como, embora as pessoas costumassem referir-se ao movimento piquetero como via de acesso ao plano, o estar com os piqueteros podia ser muito mais do que inscrever-se no plano. Em outro trabalho, mostrei que essas "razões" e suas tensões não eram alheias ao universo social que eu estudava: o compromisso e a necessidade, a solidariedade e o interesse eram alguns dos termos nativos nos quais o quadro de oposições apresentado acima se expressava, como também algumas das premissas morais que regulavam relações e posições no interior dos movimentos (Quirós 2007).

Pretendo agora avançar sobre esse problema em outra direção. Uma das ideias que defendo neste artigo é a de que os termos dicotômicos e excludentes nos quais se fechou a reflexão acadêmica derivaram em: a) uma redução da importância do poder propriamente "político" que encerra a ordem "econômica", ou seja, uma falta de percepção do caráter não-excludente da distinção entre política e economia; ${ }^{16}$ b) uma impossibilidade de se dar conta de dimensões que escapam aos próprios termos da distinção 
e, portanto, de incluí-las na análise. Deixarei o segundo problema para o fim do artigo. Nas próximas páginas, detenho-me no primeiro problema e argumento que, para prescindir de visões instrumentalistas e reducionistas do engajamento político, não é necessário "carregar nas tintas" na ideologia e/ou na moralidade; não é preciso adicionar grandes palavras de ordem, alheias às experiências concretas, nem motivações "não-econômicas" para transformar os movimentos em movimentos sociais, e suas ações em ações coletivas.

Sustento - voltando a Florencio Varela - que, se partirmos do lugar ocupado por "recursos econômicos" como o plano no dia-a-dia de nossos interlocutores, e se considerarmos seriamente a forma como esses recursos são vividos, poderemos ver como por meio deles são gestados práticas, relações, sistemas de direito e de valor que adquirem um caráter "político" sui generis. Tomando como ponto de partida esta perspectiva, defendo que, em relação ao engajamento em movimentos piqueteros, os planos não podem ser tomados como única "razão", ou tampouco como razão secundária ou aparente, senão como aquilo que para muitos incorpora essas organizações no horizonte de possibilidades e que - como pretendo demonstrar - transforma os piqueteros em algo "político" e "econômico" ao mesmo tempo. Para tanto, volto a meu material etnográfico.

\section{A luta como critério de merecimento: os movimentos além da "mediação"}

Segundo Matilde Aguirre, só quando - seis meses depois de estar frequentando as manifestações como voluntário no MTR - Juan recebeu seu plano, ela começou a "respeitar esses piqueteros". E desde então ela participa das passeatas em substituição a seu marido quando ele está fazendo algum bico. A possibilidade de mandar um substituto às manifestações — prática corrente entre muitos movimentos - indica não só a importância conferida pelas organizações à quantidade mobilizada, mas também a relevância do comparecimento para as próprias pessoas que se comprometem com os protestos. Essa relevância pode advir do plano, mas também do cumprimento das obrigações - o que se considera legítimo - e da atenção às expectativas dos outros, porque, como ouvi dizer várias vezes: Aqui, conseguimos as coisas lutando.

O comparecimento às manifestações - registrado em planilhas ao início e ao fim de cada uma delas - é também o critério para a distribuição de outros benefícios, como as cestas de mercadorias que as organizações 
recebem do governo provincial e nacional. Certa vez, no centro do pátio de uma das sedes do MTR, deparei-me com três listas de nomes e sobrenomes sobre um quadro, encimadas por um cartaz que anunciava: "Manifestações pelas cestas: 16/11 - 23/11 - 10/12 - 14/12 - 20/12". Verifiquei que eram aproximadamente 90 pessoas no total: 50 para a "cesta grande", 40 para a "cesta pequena". Num primeiro momento, os números me pareceram enigmáticos, mas depois saberia que as datas se referiam às manifestações computadas para a cesta do mês: Quem vai a todas as manifestações - explicou-me um companheiro do movimento - recebe a cesta grande; de cinco manifestações, quem falta a duas ou mais recebe a pequena.

O tamanho da caixa indica então diferenças no tempo e no esforço dedicados por cada companheiro à organização. Mais ainda: indica o que cada um merece em consequência do que deu. O movimento constrói um espaço de criação de direitos e merecimentos baseados e expressos num critério específico: a luta - quantificada, entre outras coisas, no número de protestos a que cada um comparece. Sem luta não há direito - costuma se dizer no MTR. Não agradeça, companheiro, pois você ganhou o plano com a luta - proclamam alguns dirigentes, como mostra o trabalho de Manzano (2005:14). A luta geralmente é apresentada - e reivindicada - em relação e por oposição a outros critérios competidores, como o das UGLs ou o do Partido Justicialista.

Embora escape aos limites deste artigo a tarefa de apresentar etnograficamente cada um desses espaços em funcionamento, menciono que os representantes das UGLs costumam reivindicar publicamente a necessidade como critério de distribuição dos planos — necessidade esta quantificada como número de filhos de cada aspirante. Já nas redes do Partido Justicialista, planos e outros recursos circulam como parte dos favores que militantes e cabos eleitorais fazem a seus vizinhos, parentes, amigos e/ou bases eleitorais, os quais expressam, por sua vez, seu agradecimento por meio de outro favor, como o apoio ou o respaldo político. Claro que a luta, a necessidade e os vínculos pessoais de favor e agradecimento não operam de forma exclusiva em cada uma dessas organizações. Diria, ao contrário, que esses princípios convergem cotidianamente, não sem tensões. Interessa-me destacar que, embora os recursos (estatais) em jogo sejam os mesmos, são diferentes os princípios e os valores agenciados em cada espaço para se fazer merecedor deles e justificar o merecimento. ${ }^{17}$

O quadro dicotômico entre razão material e razão político-moral que apresentei inclui uma versão normativa e "rupturista" sobre a relação (ou não-relação) entre os movimentos e o Estado - visão que pode ser expressa em termos de heteronomia (econômica) vs. autonomia (política). Partindo de 
uma concepção de ação coletiva como ação da Sociedade "contra" o Estado, "à margem" ou "apesar" dele, tende-se a lamentar a centralidade adquirida pelos recursos e programas de assistência para as organizações, tratando-a como cooptação e dependência, institucionalização dos movimentos, perda de sua autonomia ou de seu potencial transformador (cf. Svampa 2004; Grimson 2004; Massetti 2004:130; Svampa \& Pereyra 2004:60 e 194; Mazzeo 2004:139; Campione \& Rajland 2006:313-ss). Com base no que se expôs nesta seção, interessa-me assinalar outra aresta desta "dependência": a luta, como critério de merecimento, revela que, a partir de recursos como o plano, são tecidas relações e instituídos sistemas de direito que escapam às fórmulas do próprio Estado. No caso dos movimentos, esse escape aparece levado ao extremo, como se pode ver na análise de Manzano (2007): o bloqueio de estradas e a passeata (ações contra o Estado) instalaram-se como uma forma de reivindicar e obter recursos do Estado. A partir da luta como critério de merecimento, proponho então revisar a oposição autonomia/heteronomia ${ }^{18}$ e sugiro que estejamos dispostos a acolher o poder criador - e não só cooptador - das políticas públicas em relação à gestação da mobilização e do engajamento político.

Esse escape e esse poder criador também se dão em outro plano, que me interessa particularmente: o da dimensão vivida da relação entre o movimento e as pessoas que dele participam. Ainda que todos os meus interlocutores em Florencio Varela saibam que os planos são programas governamentais, é curioso que o plano seja cotidianamente pensado - e referido - como "da UGL" ou "dos piqueteros". Certa vez, vi uma jovem preocupada com as eventuais consequências de ter iniciado suas férias no MTR sem antes ter avisado o delegado da sua sede. ${ }^{19}$ Conforme me disse, uma "assistente do governo" tinha passado pelo refeitório e não encontrara gente trabalhando: Podem acabar tirando o plano da gente — disse-me a jovem. Quem? — perguntei. Não sei - respondeu - acho que o pessoal do movimento.

Naquele momento, sua resposta não fez mais do que alimentar minhas dúvidas sobre o poder dos movimentos para dar baixa nos planos, e concluí que precisava resolver aquela lacuna de informação consultando alguma fonte "oficial". Percebi depois, contudo, que parte das condições de possibilidade desta dúvida residia no fato de que diariamente o plano é vivido como um recurso dado pelo movimento. É o movimento que dá o plano, que dá a cesta, registra, repassa o benefício, preenche as planilhas, reconhece o companheiro que trabalha e censura o que não trabalha. É ao movimento não ao Estado - que as pessoas reclamam ou questionam em face de uma expectativa não cumprida. É com o movimento também que as pessoas se sentem comprometidas e agradecidas. 
Nas ciências sociais, é comum a conceitualização dos movimentos - e também dos cabos eleitorais ou das organizações como as UGLs - como "mediadores" ou "intermediários" entre o Estado e os destinatários das políticas públicas (cf. Auyero 2001:93-ss; Svampa 2004:8; Grimson et alii 2003:14, 33, 76). Com base no exposto acima, assinalo que a ideia de mediação pode iluminar alguns aspectos dessa relação triádica, mas também obscurecer outros aos quais foi dada pouca atenção. Em primeiro lugar, deixa de se ressaltar o vínculo entre a população e os "mediadores" em sua dimensão vivida - vínculo que, como acabo de sugerir, pode se apresentar sob a forma diádica, do ponto de vista dos envolvidos, para quem os chamados mediadores são, em vez disso, os doadores diretos.

Em segundo lugar, recuperando a advertência de Goldman (2006:275), podemos dizer que, no contexto de uma relação entre três elementos, ao qualificarmos um deles como "mediador", pressupomos como mais importante uma das relações - a da população com o Estado - a serviço da qual estaria o termo médio. Nesse movimento, o "mediador" fica reduzido a um intermediário ou a um canal (entre Estado e população), o que encobre uma característica fundamental que venho assinalando: seu poder de criação. O de criar, por exemplo, critérios e valores específicos para dar. Em seu estudo sobre o que entende por "práticas clientelistas" do peronismo, Auyero (2001:157) argumenta que "os mediadores não são somente intermediários, mas figuras cardinais na produção e na reprodução de uma maneira especial de distribuir bens, serviços e favores". Recuperando essa afirmação, acrescento aqui que a ideia de mediação lança uma sombra sobre o fato de que as distintas maneiras de distribuir são também maneiras específicas de merecer e fazer merecer - a luta, a necessidade, o favor - e são, ademais, sistemas diferenciados de obrigações e direitos entre os que, conforme a ocasião, recebem e dão. ${ }^{20}$

\section{Estar ocupados: a política na economia}

Quando o conheci, Juan Aguirre cumpria as quatro horas diárias de trabalho que lhe correspondiam como contraprestação de seu plano, fazendo consertos em um dos locais do Movimento Teresa Rodríguez. Frequentava as passeatas e participava das assembleias semanais de sua sede. Além disso, durante as primeiras quatro semanas que passei em Varela, pude ver Juan e toda a sua família dedicarem-se quase integralmente às atividades associadas à ocupação do local que funcionaria como centro cultural dos possíveis beneficiários das bolsas. Naquela época, as idas e vindas dos 
Aguirre, de sua casa ao lugar ocupado, num bairro vizinho, foram também as minhas. Ao menos a princípio, um lugar ocupado não pode ficar só, porque pode ser tomado por outros, reclamado pelo proprietário ou ser desalojado. Portanto, trata-se efetivamente de um verdadeiro ato de ocupação, sendo esta a tarefa central desde o primeiro dia: a ocupação criou a vigilância, e a vigilância, os seguranças, a limpeza, as refeições, as finanças, os cursos, o cadastramento das crianças.

Juan Aguirre levara alguns colchões e cobertores e encabeçava a segurança noturna. Durante o dia, dedicava-se a fazer consertos na infra-estrutura, em instalações de luz, água e sanitários. Matilde ia de manhã, para a troca de turnos e para preparar o almoço ou o lanche da tarde. Embora frágeis e repletos de dúvidas - sobre as bolsas do governo, sobre uma eventual desocupação forçada - esses primeiros dias foram fundamentais. Vero - a mais velha dos sete filhos do casal Aguirre - passou a ser uma espécie de líder natural da comissão de adolescentes que se incumbiu da ocupação. Ela fazia a inscrição dos jovens que, dia após dia, chegavam ao local dizendo: Venho por causa das bolsas; atendia às mães que, com a fotocópia do documento de identidade na mão, iam inscrever seus filhos; organizava os turnos da segurança; cuidava da contabilidade do suprimento destinado pelo MTR ao refeitório do local; tomava nota dos gastos, das contribuições, de quem e quantos ficavam para comer. Em sua bolsa, ia acumulando esses controles que o movimento algum dia pediria aos ocupantes do lugar, e que o governo pediria ao movimento. Desde o início, o governo era um terceiro ao qual a própria ocupação se dirigia: as atividades desenvolvidas na ocupação sustentavam-se numa relação intrínseca entre ter um lugar próprio e a possibilidade de obter as bolsas.

Duas semanas após a ocupação, Claudia, dirigente do MTR, chegou ao local anunciando a convocação para uma passeata em direção ao Ministério de Desenvolvimento Social: As bolsas existem, mas não nos querem dar. Temos que lutar por elas - disse certa tarde aos jovens da comissão. Dois dias mais tarde, Vero Aguirre foi quem anunciou a realização da passeata em uma reunião a que compareceram cerca de 70 pessoas: Não é obrigatória disse na ocasião - mas é importante que vocês venham, principalmente os jovens, porque é uma passeata dos jovens para reivindicar as bolsas. Dias depois, aproximadamente 200 pessoas percorriam um caminho conhecido pelos companheiros do MTR: concentraram-se às 8 da manhã na estação de Varela, tomaram o trem até a estação Constitución, na capital, e foram em passeata até o Ministério. Lá, enquanto esperavam à porta, interrompendo o trânsito, Claudia e um grupo de mães foram atendidos por um funcionário. Meia hora depois, quando saíram do edifício, o resultado da 
reunião parecia pouco alentador: Me disseram que não estão dando bolsas individuais e que não têm a intenção de dar, parece que só podem financiar projetos coletivos - disse-me Claudia enquanto os manifestantes tomavam o caminho de volta.

No dia seguinte, fui a Florencio Varela e, antes de chegar ao local, passei pela casa dos Aguirre, que estava mais silenciosa que de costume. Juan quase não tinha voz: uns dias antes fora ao hospital e, apesar de lhe terem recomendado repouso absoluto, continuou fazendo a segurança noturna. É uma vergonha - disse. Agora, o que vão dizer aos meninos? Como é que alguém pode dizer a todos esses meninos que não há bolsas? Com tudo o que fizemos, vê como está a minha voz? Minha filha Vero vai todos os dias a esse lugar. Tudo isso pra nada... Matilde escutava, o olhar perdido, até que interveio: Agora vai tudo por água abaixo — disse. Os jovens estavam no projeto por causa das bolsas.

A desilusão de Matilde e Juan fazia da ocupação um fracasso. E mostrava, uma vez mais, a lógica de expectativas e obrigações recíprocas em jogo: eles julgavam ter dado tudo de si trabalhando na ocupação e agora o movimento não cumpria o prometido. Algumas horas mais tarde iniciava-se no local a reunião convocada por Claudia para anunciar os resultados da passeata do dia anterior. Com a presença de cerca de 80 pessoas, a dirigente tomou a palavra e explicou que, embora o governo não tivesse uma política de bolsas, o ministério havia se comprometido a colocar à disposição capacitadores para que os jovens aprendessem a fazer projetos: Nós apresentamos esses projetos e eles subsidiam os cursos, ou o que quer que seja.

Recordo ter-se feito silêncio. Vero queixou-se, salientando que durante o dia vários pais tinham aparecido para buscar os papéis de seus filhos: Me disseram que o movimento andava contando mentiras, prometendo coisas. Outro me disse que fazíamos seus filhos trabalharem no local e que as bolsas não existiam. Claudia escutava constrangida. Em uma das janelas do lugar, uma mulher tinha nas mãos uma listinha com os nomes dos jovens cujos documentos em fotocópias lá deixadas deveria buscar. Eram os vizinhos que ela havia inscrito para terem acesso às bolsas: Eu quero saber por que disseram que ia ter bolsas se o governo agora diz que não vai ter — disse a mulher. De novo, o silêncio. E, subindo o tom de voz, prosseguiu: Porque todos nós que estamos aqui estamos porque queremos um lugar para que os meninos deixem de ficar pelas ruas, e agora vocês dizem que não há bolsas. Vários murmúrios aprovaram a intervenção dessa mulher que, como Juan e Matilde, tratava as bolsas como um compromisso do movimento, não do governo. Claudia respondeu: Eu tinha dito que tinha que fazer projetos, disse isto na primeira reunião, mas vamos continuar lutando por essas bolsas; a 
gente, que está no movimento, sabe que não se consegue nada com uma única passeata.

Claudia seguiu explicando que pensara num "projeto para fazer molho de tomate", para que os jovens que queriam trabalho tivessem alguma renda; falou também de uma professora de inglês que haviam conseguido para que desse aulas; e de uma oficina de rádio que funcionaria no local com a assessoria de dois estudantes de jornalismo: Portanto, estão abertos novos cursos - concluiu, fazendo uma pausa. Percebi que suas palavras não se voltavam ao passado; ao contrário, continuavam, apesar de tudo, focadas no futuro para o qual, desde o princípio, a ocupação se orientava. Para minha surpresa, as intervenções de outros pais e jovens também seguiram essa lógica, expressando uma preocupação compartilhada pela continuidade da ocupação: Os meninos têm que continuar dando plantão? — perguntou uma mulher. Vamos continuar a servir o lanche? - perguntou Vero. A própria Matilde Aguirre perguntou pela oficina de artesanato que estaria sob a sua responsabilidade: Pode ser nas quartas-feiras, à tarde?

Enquanto os pais se dispersavam, os filhos faziam fila para que Vero os inscrevesse nas novas oficinas de rádio e inglês. A lista, então, chegaria a 250 inscritos. Os outros adolescentes da comissão estavam ali, ao redor da mesa, ajudando Vero. Os mesmos rostos que eu tinha visto na passeata do dia anterior, agitando a bandeira do movimento. Só então reparei que nenhum deles comentara coisa alguma sobre a reunião no ministério. Pelas ruas do centro de Buenos Aires, os jovens tinham rido e, acima de tudo, tinham se divertido. Era a passeata deles, eles a lideravam, eles eram o rosto visível da manifestação. Ao lado da ocupação desse lugar, de tudo o que ali faziam, o resultado da reunião parecia ser algo secundário. É que, embora o governo (e as bolsas) fosse um terceiro para o qual a ação se orientava, para alguns dos que estavam naquela última reunião, a ocupação passara a ter sentido por si mesma. A ocupação tinha criado os almoços, os lanches, os plantões, os papéis, as finanças, a comissão dos meninos. Se, como disse, se tratava de um autêntico ato de ocupação, assim o era num sentido mais amplo: as pessoas ocupavam fisicamente o lugar, mas também estavam ocupadas. Estavam fazendo coisas.

\section{Final: o "prazer de fazer" no engajamento político}

Volto então a alguns pontos de meu argumento. Primeiro: tal como a luta como critério de merecimento, a ocupação nos mostra que a centralidade dos recursos estatais — neste caso, as bolsas — não é oposta à criatividade dos movimentos. 
Opor heteronomia (econômica) e autonomia (política) obscurece o fato de que, por meio de objetos como planos e bolsas, da maneira de obtê-los, distribuir e merecer, as organizações fazem algo mais que "mediar": produzem relações e ações com efeitos sui generis. Segundo: mediante a ocupação, volto a defender a esterilidade de se oporem interesse (econômico) e compromisso (político) no que se refere às motivações que conduzem e sustentam o engajamento num movimento. Originalmente, a possibilidade de obter um recurso estatal foi o que deu fundamento à ocupação. As bolsas não chegaram, mas para o que tinham gerado não havia — não houve - volta: geraram a ocupação em si e, com ela, um espaço, uma trama de relações, um conjunto de rotinas e sentidos. As situações observadas no contexto da ocupação evidenciam que aquilo que os movimentos de desempregados produzem e fazem circular são recursos para sobreviver (planos, bolsas, cestas de mercadorias) e também formas de viver. Num mundo onde trabalhar é algo valorizado, onde a vagabundagem constitui uma das acusações mais ostentadas, estar com os piqueteros pode significar estar ocupado, pode ser o que dá sentido à vida.

A ação gerada na obtenção de recursos de subsistência, o compromisso produzido nesse fazer, os modos de subsistir — que são também modos de existir socialmente - fazem dos movimentos piqueteros, ao mesmo tempo, "economia" e "política", e os levam, de fato, a ultrapassar "economia" e "política". A ocupação daquele local como sucessão de eventos convida-nos não só a conjugar as categorias do consenso dicotômico com que iniciei este artigo, mas também a prescindir delas. Isto implica pensar, por exemplo, que parte das condições de possibilidade da ocupação do local foram as energias e a satisfação investidas em e por esse "estar ocupados". E, se consegui transmitir ao leitor algo do espírito que animou os protagonistas da ocupação durante essas semanas, terá sido possível notar que para os Aguirre, para Vero e para os jovens da comissão os plantões, o refeitório, as inscrições para os cursos e as bolsas, as reuniões, a contabilidade eram atividades desenvolvidas com prazer, simplesmente com paixão. Esse prazer é aquilo que não cabe na grade economia/política e que, por razões que seria interessante mapear teoricamente, temos encontrado dificuldade em sociologizar.

Max Weber (1989:74-ss) refere-se à "paixão" como uma qualidade decisiva de quem tem vocação para a política. Esclarece imediatamente que "não se é político por ser apaixonado, a menos que a paixão esteja a serviço de uma 'causa'". Alguns trabalhos recentes que se propõem a incorporar as "emoções" ao estudo dos movimentos sociais assinalam, entre outras coisas, a atração e o entusiasmo que podem ser gerados pela crença numa causa, pela expectativa de mudar certa ordem de coisas ou pelo empoderamento advindo da participação em ações de protesto (Jasper 1998:406). ${ }^{21}$ Mesmo 
quando a devoção a uma "causa" ou o sentimento de "ganho de poder" possa estar presente nas situações vinculadas à ocupação, estou tentando chamar a atenção para outra força, mais primária caso se queira, que Florence Weber (1989) formula como o "prazer de fazer", ou seja, o gosto despertado no e pelo próprio fazer.

O quadro dicotômico que atravessa o campo da ação coletiva — e também, de um modo mais geral, o do estudo da política entre setores sociais populares — inclui a suposição de que a explicação do engajamento está naquilo que, material, político ou moral, as pessoas buscam e/ou obtêm (recursos de subsistência, reconhecimento, pertencimento, empoderamento, resistência, identidade). Definitivamente, em sua investida contra a razão material, a razão político-moral acabou substituindo uma explicação teleológica por outra. Entendo que o desafio é o de escapar a estes e a outros reducionismos, e que a etnografia é uma ferramenta privilegiada nesta tarefa, uma vez que nos abre o mundo social em seu fazer e em suas contradições.

A ocupação de que tratei é um exemplo: para qualquer um que acompanhe essas experiências em sua dimensão vivida seria difícil reduzi-las a rótulos como necessidade (econômica) e/ou compromisso (político). A linguagem de nossos interlocutores é outra chave do conhecimento etnográfico que nos impede de estereotipar o jogo social: no início deste artigo, assinalei a preeminência da expectativa de obter um plano na forma como as pessoas me narravam sua aproximação com um movimento piquetero. Necessidade era de fato o termo nativo com que muitos se referiam ao que a literatura desprezaria, em outro contexto, como explicação economicista: Eu vim aqui por necessidade - diziam-me alguns de meus interlocutores; A primeira coisa que te traz é a necessidade - diziam-me outros. É curioso que, imediatamente depois, passassem a indicar o momento em que tinham começado a sair em passeata; continuavam me contando cada uma das atividades que tinham realizado dentro do movimento no início; descreviam as atividades e as rotinas que iam se sucedendo depois; até que, como quem sintetiza uma história numa única frase, concluíam: E aí fui me envolvendo...

Entendo que é hora de outorgar a esse envolver-se - que, uma vez mais, não podemos rotular nem como "econômico" nem como "político" — um lugar analítico próprio, não só no estudo da ação coletiva, mas também no do engajamento em sentido amplo. E prestar atenção na força do prazer de fazer capaz de ser um primeiro passo nessa direção: o prazer de fazer está no cerne das condições de possibilidade daquela ação de ocupação; na forma como a família Aguirre pôde abandonar tudo durante essas semanas; na maneira como Juan, no início, pôde "viver dia e noite" no piquete; no modo como, enfim, dia a dia, além da necessidade e do compromisso, as pessoas 
simplesmente se envolvem - numa "ação de protesto", num "movimento social", num "partido", na própria "política".

Recebido em 03 de dezembro de 2007

Aprovado em 10 de junho de 2008

Tradução de Sergio Benevides

Julieta Quirós é doutoranda do PPGAS/ Museu Nacional/ UFRJ. E-mail: <juquiros@hotmail.com>

\section{Notas}

* Este artigo desenvolve alguns pontos de minha dissertação de mestrado, defendida no PPGAS, Museu Nacional, em fevereiro de 2006, e publicada em livro na Argentina, no contexto da coleção Serie Etnográfica. Agradeço a Guillermo Quirós, Lygia Sigaud, Rosana Guber e aos/às avaliadores/as anônimos/as de Mana a leitura cuidadosa e os proveitosos comentários sobre a primeira versão; também a Federico Neiburg, Moacir Palmeira, Fernando Balbi, Mauricio Boivin, Ana Rosato, Marco Fernandes, Marcelo Ernandez, Marcelo Rosa, Virginia Manzano e María Inés Fernández Álvarez que, em distintas instâncias de diálogo e interlocução, nutriram os argumentos que apresento neste texto.

${ }^{1}$ Em 1997, produziram-se 140 bloqueios de estradas em nível nacional, enquanto em 2002 o número aumentou para 2.336 (Manzano 2007:2). Sobre o deslocamento do piquete e das organizações de desempregados, do interior do país para a Grande Buenos Aires e para a Cidade de Buenos Aires, veja-se Svampa \& Pereyra 2004; Masseti 2004.

${ }^{2}$ Esta explosão está ligada, além disso, a um contexto de alta mobilização que, em dezembro de 2001, obrigou o presidente eleito a renunciar, tornando mais agudo o processo de instabilidade política e ebulição social que se prolongou durante todo o ano de 2002 e que se expressou por meio de diversas modalidades de protesto — piquetes, assembleias nos bairros, mobilizações de poupadores, ocupação de fábricas.

${ }^{3}$ Com uma população de 348.767 habitantes, Florencio Varela está a $24 \mathrm{~km}$ da Cidade de Buenos Aires. Segundo o Instituto Nacional de Estatísticas e Censos, faz parte do "Conurbano IV", a região mais pobre e com os índices mais elevados de desemprego da Grande Buenos Aires. 
${ }^{4}$ Neste artigo, à exceção de fragmentos de discurso indireto, a fala de meus interlocutores não está entre aspas, mas iniciada com maiúscula, para indicar que outro - e não eu - a enuncia. Sobre esse recurso narrativo e suas implicações, cf. Quirós 2006:43-ss. Palavras e expressões em itálico referem-se a termos nativos fora de contextos de situação específicos.

${ }^{5}$ O Partido Justicialista — expressão institucional do movimento político conhecido como peronismo ou também justicialismo - governa o distrito de Florencio Varela desde a abertura democrática (1983) e a província de Buenos Aires desde 1987.

${ }^{6}$ Algumas delas: historiar a origem e o desenvolvimento do piquete como forma de protesto (Isman 2004; Svampa \& Pereyra 2004; Oviedo 2001); analisar os potenciais políticos das organizações de desempregados e sua relação - ou não-relação - c om o Estado (Lenguita 2002; Grimson 2004; Svampa \& Pereyra 2004.; Svampa 2004; Negri \& Cocco 2003; Colectivo Situaciones 2003; Hopstein 2003; Dinerstein 2001); estudar novas identidades, novas formas de sociabilidade e novas formas de fazer política gestadas nos movimentos (Cross \& Cató 2002; Masseti 2004; Svampa \& Pereyra 2004; Delamata 2004); inscrever o fenômeno em processos mais amplos de protesto social (Auyero 2002a; Schuster \& Pereyra 2001; Scribano \& Schuster 2001; Campione \& Rajland 2006); inscrever a ação das organizações em outras experiências e tradições associativas ligadas ao bairro (Grimson et alii 2003; Svampa \& Pereyra 2004; Delamata 2004).

${ }^{7}$ Cross e Cató (2002:88) ressaltam que "se produziu uma passagem da definição negativa 'não tenho trabalho' para outra, positiva, 'sou piquetero'". Lenguita (2002:61) assinala que, "para seus protagonistas, ser piquetero significa que sua identidade deixou de estar associada a um trabalho, para estar, agora, designada pelo que se faz: bloquear a estrada". Sobre o piquete como instância de construção de uma nova identidade coletiva, veja-se também Massetti (2004:52-94); Svampa \& Pereyra (2004:168-ss.); Grimson et alii (2003:74); Barbetta \& Lapegna (2001:238-ss).

${ }^{8}$ Embora Auyero utilize o referencial conceitual das teorias da ação coletiva, propõe em seus trabalhos um recorte biográfico que procura dar conta das motivações e das percepções daqueles que participam de ações de protesto. A partir da antropologia, Manzano distancia-se dos enfoques sobre protesto e ação coletiva. Articulando diversas escalas de processos políticos, tradições associativas e vivências cotidianas de seus interlocutores no campo, a autora dá conta das condições sócio-históricas por meio das quais o piquete se instalou como forma reconhecida de anunciar um conflito social perante o Estado. Em outros trabalhos recentes que também exploram aspectos da vida cotidiana no interior de organizações piqueteras (por exemplo, Ferraudi Curto 2006), o "ator coletivo" aparece desagregado em sujeitos concretos. Cabe assinalar que, embora o recorte e o sujeito presentes nos trabalhos de Svampa \& Pereyra (2004) e Grimson et alii (2003) sejam "organizações", estes autores procuram conectar a experiência piquetera a outras trajetórias e condições associativas ligadas ao bairro.

${ }_{9}^{9}$ Desde 1996, os governos nacional e provincial lançaram diversos tipos de planos de emprego: subsídios de 150 pesos mensais (50 dólares) que requerem do 
beneficiário uma contraprestação de quatro horas diárias de trabalho em projetos comunitários, produtivos ou em formação educativa.

${ }^{10}$ No ano 2000, o governo nacional determinou que a gestão dos planos — até então concentrada nas entidades municipais e nas redes do Partido Justicialista pudesse ser assumida também por organizações da "sociedade civil". Nesse contexto, a maioria das organizações piqueteras constituiu-se em organizações não-governamentais, passando a gerir seus próprios padrões de planos sociais, bem como a organizar a contraprestação em atividades dentro dos movimentos.

${ }^{11}$ Puntero é o termo de sentido comum para se referir aos militantes locais que trabalham para algum candidato ou linha partidária, mobilizando bases e recrutando eleitores [o equivalente, em certa medida, no Brasil, aos cabos eleitorais]. Alguns autores sustentam a oposição puntero/piquetero como modalidades opostas de vínculo político: lógica "autogestora" dos movimentos piqueteros vs. lógica "clientelista" da rede peronista (Delamata 2004:25); ou "espaços de verticalidades" e "lógica do favor", no caso do puntero, e "espaços de horizontalidades" e "lógica dos direitos", no caso do piquetero (Mazzeo 2004:76-77). Outros destacam a preocupação acerca da possível influência que a "cultura clientelista" (Grimson et alii 2003:74-76) estabelecida pelo peronismo exerceria sobre as organizações piqueteras. Outros, finalmente, ressaltam a oposição como experiências cotidianas de confronto entre organizações de desempregados e redes do peronismo (Svampa \& Pereyra 2004:53). Entendo que esse confronto opera em níveis e circunstâncias específicos - por exemplo, o da competição pela obtenção de recursos e pela adesão das pessoas que os recebem. Não obstante, a codificação de todas as relações por meio desses rótulos pode estancar uma realidade complexa e oscilante e nos levar a perder a perspectiva dos que são denominados - muitas vezes por outros de punteros e piqueteros.

12 À exceção de pessoas publicamente conhecidas, os nomes próprios são fictícios.

${ }^{13}$ Enquanto o piquete se refere ao ato de bloquear e ocupar estradas, pontes e ruas, a passeata indica uma modalidade de protesto na qual a coluna mobilizada percorre um caminho predeterminado até chegar a um ponto de destino específico, que costuma ser um órgão do governo. Nos últimos anos, os movimentos piqueteros vêm recorrendo mais à passeata do que ao piquete, em parte pelo descrédito deste perante a opinião pública. Neste trabalho, portanto, falaremos mais de passeatas que de piquetes.

${ }^{14}$ Retomo esta expressão com que Sigaud (2004:16-ss) apresenta, em seu estudo sobre ocupações de terra no Brasil, a pergunta sobre a criação de disposições para ocupar entre os trabalhadores rurais (veja-se também Sigaud 2005).

${ }^{15}$ Thompson (1998:203-ss) adverte sobre o empobrecimento do termo "economia moral" a partir desta leitura. Adverte também sobre os perigos de estendê-lo a outros contextos sócio-históricos e transformá-lo em "teoria". 
${ }^{16}$ Uso aqui os termos "político" e "política" no mesmo sentido que meu interlocutor nesta discussão conceitual, ou seja, o campo intelectual e acadêmico sobre ação coletiva e movimentos sociais, para o qual "política" é sobretudo ação e transformação da ordem estabelecida. Também neste ponto, o discurso dos cientistas sociais está em sintonia com o dos dirigentes das organizações. Cabe mencionar que não é objeto deste artigo explorar o sentido de "política" do ponto de vista de meus interlocutores de campo, que operam situacionalmente com múltiplas acepções do termo, entre elas a mencionada acima, e para os quais não necessariamente nem em todo momento a participação em um movimento piquetero é considerada algo "político" (cf. Quirós 2006:123).

${ }^{17}$ Cabe mencionar, por outro lado, que cada um desses critérios de merecimento qualifica moralmente os recursos em jogo: se é verdade — como disse no início deste texto - que as pessoas circulam por espaços não necessariamente contraditórios nem excludentes, também não se trata de espaços indiferenciados, muito menos indiferentes. Em Varela, muitos consideram legítimo receber um plano da UGL, mas não um plano dos piqueteros: Prefiro procurar trabalho digno a andar nesse caminho; Essas passeatas são coisa para vagabundos — diziam alguns de meus interlocutores. Inversamente, para outros, estar com os piqueteros é a forma de obter um plano ou uma cesta de mercadorias sem sentir vergonha: A mim ninguém deu nada, o que eu tenho, consegui lutando — costuma gabar-se Juan Aguirre.

${ }^{18}$ Recupero a revisão desta oposição autonomia/heteronomia com base nos trabalhos de Sigaud $(2004,2005)$, Rosa (2004) e Ernandez (2006), que analisam a relação entre o Estado brasileiro e os movimentos de ocupação de terra como relação de interdependência.

${ }^{19}$ As relações cotidianas no interior das organizações piqueteras estão marcadas por sistemas de deveres e direitos formalizados que contêm, em muitos casos, elementos das relações de trabalho. Assim, por exemplo, no registro do comparecimento a passeatas e a atividades que correspondem à contraprestação do plano, os movimentos costumam contemplar faltas justificadas em função de ocupação em bicos, licença-maternidade, doença e férias. Como desenvolvo em outro texto (Quirós 2007), estes elementos, bem como a própria referência a estar com os piqueteros como trabalho, constituem uma das arestas da imbricação entre política e economia analisada neste artigo.

${ }^{20}$ Outras discussões a respeito da noção de "mediador" podem ser encontradas no trabalho de Rosa (2004:249-ss).

${ }^{21}$ Este trabalho e outros mais recentes (Goodwin et alii 2001; Goodwin \& Jasper 2004) têm o mérito de questionar uma tradição acadêmica que fez dos protagonistas das ações coletivas criaturas planas e unidimensionais. Não obstante, ao serem em grande parte propostas de caráter programático, voltam a cair em certo formalismo, agora falando de "emoções". Tudo é apresentado como se as "emoções" — que em alguns casos são inclusive enumeradas - viessem a se incorporar como nova "variável", empiricamente delimitada e delimitável, ao campo conceitual específico — de "oportunidades políticas", "mobilização de estruturas", "recursos", "marcos", "redes", "identidades coletivas" — dos movimentos sociais. 


\section{Referências bibliográficas}

ALMEYRA, Guillermo. 2004. La protesta social en la Argentina (1990-2004). Buenos Aires: Peña Lillo, Ediciones Continente.

AUYERO, Javier. 2001. La política de los pobres. Las prácticas clientelistas del peronismo. Buenos Aires: Prometeo. - 2002a. La protesta. Retratos de la beligerancia popular en la Argentina democrática. Buenos Aires: Libros del Rojas.

- 2002b. "La vida en un piquete. Biografía y protesta en el sur argentino". Revista Apuntes - СЕСур, 18. Disponível em http://www.apuntescecyp-org/N8-Auyero.htm. Acesso em 20/07/2005.

- 2004. Vidas beligerantes: dos mujeres argentinas, dos protestas y la búsqueda de reconocimiento. Buenos Aires: Universidad Nacional de Quilmes.

BARBETTA, Pablo \& LAPEGNA, Pablo. 2001. "Cuando la protesta toma forma: los cortes de ruta en el norte salteño". In: N. Giarraca (org.), La protesta social en la Argentina: transformaciones económicas y crisis social en el interior del país. Buenos Aires: Alianza Editorial. pp. 231-257.

BECCARIA, Luis \& LÓPEZ, Néstor. 1996. Sin trabajo. Las características del desempleo y sus efectos en la sociedad argentina. Buenos Aires: Losada.

BRUBAKER, Rogers \& COOPER, Frederik. 2000. "Beyond 'identity'". Theory and Society, 29:1-47.

CAMPIONE, Daniel \& RAJLAND, Beatriz. 2006. "Piqueteros y trabajadores ocupados en la Argentina de 2001 en adelante: novedades y continuidades en su participación y organización en los conflictos" In: G. Caetano (org.),
Sujetos sociales y nuevas formas de protesta en la historia reciente de América Latina. Buenos Aires: CLACSO. pp. 297-330.

COLECTIVO SITUACIONES. 2003. Hipótesis 891. Más allá de los piquetes. Buenos Aires: Ediciones de Mano en Mano.

CROSS, Cecilia \& MONTES CATÓ, Juan. 2002. "Crisis de representación y identidades colectivas en los sectores populares. Acerca de las experiencias de las organizaciones piqueteras". In: O. Battistini (org.), La atmósfera incandescente. Escritos sobre la Argentina movilizada. Buenos Aires: Asociación Trabajo y Sociedad. pp. 85-100.

DELAMATA, Gabriela. 2004. Los barrios desbordados. Las organizaciones de desocupados del Gran Buenos Aires. Buenos Aires: Libros del Rojas, Eudeba.

DINERSTEIN, Ana. 2001. “El poder de lo irrealizado: el corte de ruta en la Argentina y el potencial subversivo de la mundialización". Revista del Observatorio de América Latina / OSAL, 5:11-16.

ELIAS, Norbert. 1991. Qu'est-ce que la sociologie? Paris: Editions de L'Aube.

ERNANDEZ, Marcelo. 2006. Sementes sem trincheiras: sócio-gênese das ocupações de terra no Rio de Janeiro. Relatório de pesquisa, Rio de Janeiro, Museu Nacional. 96 pp.

FERRAUDI CURTO, Cecilia. 2006. Mientras tanto: política y modo de vida en una organización piquetero. Dissertação de mestrado, IDES-UNSAM. GOLDMAN, Marcio. 2006. Como funciona a democracia. Uma teoria etnográfica da política. Rio de Janeiro: 7 Letras. 
GOODWIN, Jeff; JASPER, James \& POLLETA, Francesca (orgs.). 2001. Passionate politics. Emotions and social movements. Chicago-Londres: The University of Chicago Press.

GOODWIN, Jeff \& JASPER, James (orgs.). 2004. Rethinking social movements. Structure, meaning and emotion. Lanham, MD: Rowman \& Littlefield.

GRIMSON, Alejandro. 2004. "Piquetes en la ciénaga. Los bloqueos políticos de los cortes de ruta". El Rodaballo. Revista de Política y Cultura, 15:9-13. · LAPEGNA, Pablo et alii. 2003. "La vida organizacional en zonas populares de Buenos Aires". The Center for Migration and Development, Workins Series Paper, Princeton University, CMD Working Paper 03-15-e. Publicado na internet em: http://www.prc. utexas.edu/urbancenter/documents/ wp0315e.pdf. Acesso em 17/01/2005.

HOPSTEIN, Graciela. 2003. "Piqueteros: limites e potencialités". Revista Multitudes, 14:155-163.

ISMAN, Raúl. 2004. Los piquetes de la Matanza. De la aparición del movimiento social a la construcción de la unidad popular. Buenos Aires: Nuevos Tiempos.

JASPER, James. 1998. "The emotions of protest: affective and reactive emotions in and around social movements". Sociological Forum, 13(3):397-424 .

LENGUITA, Paula. 2002. "El poder del desempleo. Reflexiones críticas sobre la relevancia política del movimiento piquetero". In: O. Battistini (org.), La atmósfera incandescente. Escritos sobrela Argentina movilizada. Buenos Aires: Asociación Trabajo y Sociedad. pp. 51-67.

LÉVI-STRAUSS, Claude. 1967. Les structures élémentaires de la parenté. Paris: Mouton.

MALINOWSKI, Bronislaw. 1935. Coral gardens and their magic. A study of the methods of tilling the soil and of agricultural rites in the Trobriand Islands. London: George Allen \& Unwin Ltd.

MANZANO, Virginia. 2005. "Desempleo, 'piquetes' y acción estatal en Argentina: Análisis antropológico de la configuración de un campo de relaciones sociales y políticas". Publicado em Anales de la VI Reunión de Antropología del MERCOSUR (digital). - 2007. De la Matanza Obrera a Capital Nacional del Piquete: etnografía de procesos políticos y cotidianos en contextos de transformación social. Tese de doutorado, Facultad de Filosofía y Letras, UBA.

MASsetTi, Astor. 2004. Piqueteros: protesta social e identidad colectiva. Buenos Aires: Coedición Ed. de las Ciencias-FLACSO.

MAUSS, Marcel. 2003. “Ensaio sobre a dádiva. Forma e razão da troca nas sociedades arcaicas". In: Sociologia e Antropologia. São Paulo: Cosac \& Naify. pp. 183-314.

MAZZEO, Miguel. 2004. Piqueteros: notas para una tipología. Buenos Aires: Manuel Suárez Editor.

MELUCCI, Alberto. 1994. "Asumir un compromiso: identidad y movilización en los movimientos sociales". Zona Abierta, 69:153-180.

. 1995. "The process of collective identity". In: H. Jonson \& B. Kalndermans (orgs.), Social movements and culture. London: University College London Press. pp. 41-63.

NEGRI, Antonio \& COCCO, Giuseppe. 2003. Diálogo sobre la globalización, la multitud y la experiencia argentina. Buenos Aires: Paidós.

OVIEDO, Luis. 2001. De las primeras coordinadoras al Argentinazo. Una historia del movimiento piquetero. Buenos Aires: Rumbos. 
POLLETA, Francesca \& JASPER, James. 2001. "Collective identity and social movements". Annual Review of Sociology, 27:283-305.

QUIRÓS, Julieta. 2006. Cruzando la Sarmiento. Una etnografía sobre piqueteros en la trama social del sur del Gran Buenos Aires. Buenos Aires: Antropofagia.

- 2007. "Movimientos piqueteros, formas de trabajo y circulación de valor en el sur del Gran Buenos Aires". Anuario de Estudios en Antropología Social 2006:151-160.

ROSA, Marcelo. 2004. O engenho dos movimentos. Reforma agrária e significação social na zona canavieira de Pernambuco. Tese de doutorado, IUPERJ.

SCHUSTER, Federico \& PEREYRA, Sebastián. 2001. "La protesta social en la Argentina democrática: balance y perspectivas de una forma de acción política". In: N. Giarraca (org.), La protesta social en la Argentina: transformaciones económicas y crisis social en el interior del país. Buenos Aires: Alianza. pp. 41-63.

SCRIBANO, Adrián \& SCHUSTER, Federico. 2001. "Protesta social en la Argentina de 2001: entre la normalidad y la ruptura". OSAL, 5:17-22.

SIGAUD, Lygia. 2004. "Ocupações de terra, Estado e movimentos sociais no Brasil". Cuadernos de Antropología Social, 20:11-23.

- 2005. "As condições de possibilidade das ocupações de terra". Tempo Social, 17(1):255-280.

SVAMPA, Maristella. 2004. "Relaciones peligrosas. Sobre las clases medias, gobierno peronista y movimientos piqueteros". El Rodaballo. Revista de Política y Cultura, 15:3-9. - \& PEREYRA, Sebastián. 2004. Entre la ruta y el barrio. La experiencia de las organizaciones piqueteras. Buenos Aires: Biblos.
THOMPSON, Edward P. 1998. Costumes em comum. Estudos sobre a cultura popular tradicional. São Paulo: Companhia das Letras.

WEBER, Florence. 1989. Le travail à côté. Étude d'ethnographie ouvrière. Paris: EHESS/Ed. INRA. . 1991. "Nouvelles lectures du monde ouvrier: de la classe aux personnes". Genèses, 6:179-189.

WEBER, Max. 1989. "La política como profesión". In: Política y Ciencia. Buenos Aires: Leviatán. pp. 7-95. 
Resumo

Este artigo procura, distanciando-se dos modelos formais que têm servido de eixo para os estudos sobre ação coletiva e movimentos sociais, restituir a dimensão vivida do engajamento político. Com base em análise etnográfica centrada num conjunto de bairros da Grande Buenos Aires, explora os modos múltiplos e heterogêneos - como as pessoas se envolvem nos chamados movimentos piqueteros, e indica que essas experiências ganham inteligibilidade ao serem inscritas numa trama mais ampla de relações e possibilidades de vida. A partir de uma perspectiva figuracional, o texto discute alguns pressupostos da literatura sobre organizações piqueteras, em particular, e protestos sociais, em geral; questiona a dicotomia entre razão material e razão político-moral com que se tem abordado a questão das motivações da ação coletiva; desconfia de uma oposição rígida entre Estado e movimentos sociais, apontando para o papel criador - e não só cooptador das políticas estatais; e, finalmente, propõe sociologizar o lugar do "prazer de fazer" na origem e na continuidade do engajamento político.

Palavras-chave Ação Coletiva, Etnografia, Política, Economia, Prazer de fazer, Movimentos Piqueteros, Argentina

\section{Abstract}

Distancing itself from the formal models that have served as an axis for studies of collective action and social movements, this article seeks to reinstate the lived dimension of political engagement. Basing itself on the ethnographic analysis of a set of neighbourhoods in Greater Buenos Aires, it explores the multiple and heterogeneous ways in which people become involved in the so-called movimentos piqueteros. It indicates that these experiences become intelligible through their inscription in a wider plot of relations and possibilities. Starting from a figurational perspective, the text discusses some of the assumptions of the literature on piquetero organization, in particular, and social movements more generally; it questions that dichotomy between material reason and politico-moral reason through which the question of the motivations of collective action have been addressed; it is mistrustful of a rigid opposition between the State and social movements, pointing to the creative - and not merely co-optivecharacter of state policies; and, finally, it proposes to sociologize the locus of the "the pleasure of doing" in the origin and continuity of political engagement.

Key words Collective Action, Ethnography, Politics, Economy, Pleasure of doing, Piquetero Movements, Argentina 